\title{
Contrast-Induced Nephropathy Among Patients Undergoing Cardiac Catheterization
}

\author{
Safauldeen Ahmed Alhajim ${ }^{1}$, Ahmed Sami Jebur ${ }^{2}$ \\ ${ }^{1}$ Department of Medicine, University of Basrah, Basrah, Iraq \\ ${ }^{2}$ Department of Medicine, Shifa Hospital, Basrah, Iraq
}

Email address:

safauldinhachim@yahoo.com (S. A. Alhajim)

\section{To cite this article:}

Safauldeen Ahmed Alhajim, Ahmed Sami Jebur. Contrast-Induced Nephropathy Among Patients Undergoing Cardiac Catheterization. Cardiology and Cardiovascular Research. Vol. 2, No. 3, 2018, pp. 55-60. doi: 10.11648/j.ccr.20180203.12

Received: August 25, 2018; Accepted: September 20, 2018; Published: October 17, 2018

\begin{abstract}
Contrast-induced nephropathy is an important complication after cardiac catheterization, and is associated with accelerated renal disease, increased costs, mortality rate, need for dialysis and prolonged hospital stay. This study aim is to find its incidence and risk factors. It is a cross-sectional study on 160 patients admitted for diagnostic or therapeutic percutaneous coronary intervention in Basra Cardiac Center, from March to September 2016. Data collected were a complete history, examination, blood pressure, Echo study, fasting blood sugar, lipid profile, blood urea, serum creatinine and estimated glomerular filtration rate, the type and duration of procedure, volume of contrast, and after 48 hours renal function tests were repeated. Contrast-induced nephropathy has developed in $7(8.3 \%)$ men and 5 (6.6\%) women; 11 (10.8\%) from 102 patients with dyslipidemia $(\mathrm{P}=0.03) ; 8(22.2 \%)$ from 36 with preexisting renal impairment $(\mathrm{P}=0.01) ; 11(10.9 \%)$ from 101 with hypertension $(\mathrm{P}=0.02) ; 9$ (13.6\%) from 66 diabetic $(\mathrm{P}=0.016) ; 9$ (17.3\%) from 52 smoker $(\mathrm{P}=0.002) ; 4(23.5 \%)$ from 17 alcohol drinkers $(\mathrm{P}=0.026) ; 11(11.2 \%)$ from 98 with ischemic heart disease $(\mathrm{P}=0.02)$; and $9(25.7 \%)$ from 35 with heart failure $(\mathrm{P}=<0.001)$. Also found in $1(1.6 \%)$ from 64 diagnostic procedures; $11(11.5 \%)$ from 96 therapeutic procedures $(\mathrm{P}=$ $0.016) ; 5(3.7 \%)$ from 135 patients received $<300 \mathrm{ml}$ of contrast; and $7(28 \%)$ from 25 received $\geq 300 \mathrm{ml}(\mathrm{P}=0.001)$. In conclusion contrast-induced nephropathy is aggravated by increasing age, diabetes mellitus, heart failure, ischemic heart disease, renal impairment, hypertension, dyslipidemia, smoking and alcohol use. The type of procedure (therapeutic vs. diagnostic), and large volume of contrast agent are important risk factors. Gender had no significant effect.
\end{abstract}

Keywords: Cardiac Catheterization, Contrast Media, Acute Kidney Injury

\section{Introduction}

Contrast-induced nephropathy (CIN) is defined as an absolute $(\geq 0.5 \mathrm{mg} / \mathrm{dL})$ or relative increase $(\geq 25 \%)$ in serum creatinine at $48-72 \mathrm{~h}$ after exposure to a contrast agent compared to baseline serum creatinine level, after exclusion of alternative explanation of renal impairment [1]. The incidence of CIN among the general population was found to be $(1 \%-6 \%)$, and increases by $20 \%$ or more in selected patients, especially those with previous history of cardiovascular disease $[1,2]$. CIN is the third most common cause of renal impairment acquired in hospitals after renal perfusion impairment and nephrotoxic drugs [3]. It is associated with accelerated development of end-stage renal disease, increased costs, mortality rate, need for dialysis and prolonged hospital stay [4]. CIN normally is transient and the renal function return to baseline within 5-7 days after exposure to contrast agent, less than one third of patients will develop residual renal impairment and dialysis is required in less than $1 \%$ of them. The mortality rate in patients with preexisting renal impairment rising to $17 \%$ while the rate is around $3.9 \%$ without preexisting renal impairment [5]. The pathogenesis of CIN is not so clear, but it is thought to be due to acute tubular necrosis caused by renal vasoconstriction and direct cytotoxicity to the renal tubular epithelium [6]. Many experimental and clinical studies suggest that the osmolality of contrast agent may play a role in the development of CIN [7].

There are many risk factors for CIN development divided into non modifiable and modifiable, and can be either patient related or procedure related. Older age, diabetes mellitus, preexisting renal failure, and heart failure have all been 
identified as important risk factors for developing $\operatorname{CIN}[5,8$, 9]. On the other hand, the main modifiable risk factor is the volume of contrast media. The risk of CIN was minimal in patients who received a contrast volume of $100 \mathrm{~mL}$ or less, although, in the presence of other risk factors even low dose of contrast can cause permanent renal failure especially in patient with underlying renal disease [10]. Other properties of contrast media such as viscosity and ionicity may also share the same risk for CIN [11]. Many medications such as NSAID, diuretics, aminoglycosides, metformin and vancomycin can affect renal function through many mechanisms, so withholding these medications is considered before contrast exposure [2]. The major preventive measure is the intravenous volume expansion before contrast agent administration $(0.45 \%$ or $0.9 \%$ saline, $100 \mathrm{ml} / \mathrm{h}, 12$ hours before and 12 hours after) [12, 38]. The effectiveness of sodium bicarbonate and $\mathrm{N}$-acetylcysteine in CIN prevention is controversial, and there are no recommendations to use them due to insufficient evidence of its efficacy [13, 14]. Statins were studied as potential agents to prevent CIN; one of these studies found a significant reduction in CIN incidence, and better post-procedural creatinine clearance [15]. However, till now there is no overall substantial evidence to support the use of statins before contrastenhanced interventions [11, 40]. Regarding the use of prophylactic hemodialysis after contrast exposure, there was no benefit of it as shown by three studies [16]. On the other hand, prophylactic hemofiltration appears to be effective in preventing $\mathrm{CIN}$ and is associated with improvement of in- hospital and long-term outcomes [17]. The aim of this study is to find the frequency of CIN among patients undergoing coronary catheterization, and its risk factors.

\section{Patients and Methods}

A cross-sectional study was carried out on 160 patients $\{85$ male $(53.1 \%), 75$ female $(46.9 \%)\}$, who underwent diagnostic and/or therapeutic PCI, between March 2016 and September 2016, in Basra cardiac center. The inclusion criteria were: age more than 18 years, not on nephrotoxic drugs, and had no acute illness or advanced chronic kidney disease. The exclusion criteria were: the patients who refused to consent, patients who did not have renal function test at the day of the procedure or 48 hours after it, and patients who had other cause for renal impairment.

Before the procedure full history and physical examination elicited. Blood pressure and Echo study results were recorded. Blood sample was taken for serum creatinine, fasting plasma glucose, and lipid profile estimation. GFR was calculated by the CKD-EPI Creatinine 2009 equation [18]. After the procedure, the type and duration of the procedure and the volume of administered contrast agent were recorded, and after 48 hours renal function tests were repeated for each patient. The contrast agent that was used in all procedures was Ultravist ${ }^{\circledR}$ (Bayer Health Care / Germany), each $1 \mathrm{ml}$ contains Iopromide $0.769 \mathrm{~g}$ (370mg Iodine $/ \mathrm{ml}$ ). Table 1 shows the characteristics of the patients and of the studied variables.

Table 1. Characteristics of the patients and of the studied variables.

\begin{tabular}{|c|c|c|c|c|}
\hline Variables & & Men $(\mathrm{N}=85)$ & Women $(\mathrm{N}=75)$ & Total \\
\hline \multirow{3}{*}{$\begin{array}{l}\text { Age } \\
\text { Mean }(59+18)\end{array}$} & $<45$ & $47(29.3 \%)$ & & \multirow{3}{*}{$160(100 \%)$} \\
\hline & $45-65$ & $63(39.4 \%)$ & & \\
\hline & $>65$ & $50(31.3 \%)$ & & \\
\hline Dyslipidemia & & $49(57.6 \%)$ & $53(70.6 \%)$ & $102(63.75 \%)$ \\
\hline Preexisting renal impairment & & $32(37.6 \%)$ & $4(5.3 \%)$ & $36(22.5 \%)$ \\
\hline HT & & $59(69.4 \%)$ & $42(56 \%)$ & $101(63.12 \%)$ \\
\hline $\mathrm{DM}$ & & $36(42.4 \%)$ & $30(35.3 \%)$ & $66(41.25 \%)$ \\
\hline Current smoker & & $35(41.2 \%)$ & $17(27.2 \%)$ & $52(32.5 \%)$ \\
\hline Alcohol use & & $15(17.6 \%)$ & $2(2.7 \%)$ & $17(10.63 \%)$ \\
\hline IHD & & $52(61.2 \%)$ & $46(61.3 \%)$ & $98(61.25 \%)$ \\
\hline Preexisting HF & & $31(36.5 \%)$ & $4(5.3 \%)$ & $35(21.88 \%)$ \\
\hline \multirow{2}{*}{ Type of procedure } & Diagnostic & $41(48.2 \%)$ & $23(30.6 \%)$ & $64(40 \%)$ \\
\hline & Therapeutic & $44(51.8 \%)$ & $52(69.3 \%)$ & $96(60 \%)$ \\
\hline \multirow{2}{*}{ Volume of contrast } & $<300 \mathrm{ml}$ & $73(85.9 \%)$ & $62(82.7 \%)$ & $135(84.38 \%)$ \\
\hline & $>300 \mathrm{ml}$ & $12(14.1)$ & $13(17.3 \%)$ & $25(15.63 \%)$ \\
\hline
\end{tabular}

Out of 160 patients; $41(48.2 \%)$ male and $23(30.6 \%)$ female underwent diagnostic PCI; 44 (51.8\%) male and 52 (69.3\%) female underwent therapeutic PCI; 73 (85.9\%) male and $62(82.7 \%)$ female were injected with less than $300 \mathrm{ml}$ of contrast agent; while $12(14.1 \%)$ male and $13(17.3 \%)$ female were injected with $300 \mathrm{ml}$ or more. The patients were grouped according to age: $<45$ years (47patients, $29.3 \%$ ), $45-65$ years (63patients, $39.4 \%$ ), and $>65$ years (50patients, $31.3 \%$ ). Mean age was $59 \pm 18$ years, range $40-71$ years. Criteria for dyslipidemia19 are: LDL-C level of $>140 \mathrm{mg} / \mathrm{dl}$ $(3.6 \mathrm{mmol} / \mathrm{L}), \mathrm{HDL}-\mathrm{C}<40 \mathrm{mg} / \mathrm{dl}(1.03 \mathrm{mmol} / \mathrm{L})$, or if the TC was $\geq 200 \mathrm{mg} / \mathrm{dl}(5.17 \mathrm{mmo} / / \mathrm{L})$, or the TG level $\geq 150 \mathrm{mg} / \mathrm{dl}$
$(1.69 \mathrm{mmol} / \mathrm{L})$ or on treatment with lipid-lowering drugs. Dyslipidemia was present in 102 patients; 49 (57.6\%) male, and $53(70.6 \%)$ female. The Eighth Joint National Committee (JNC8) criteria were used for the diagnosis of hypertension. 20 hypertension was found in 101 patients; 59 $(69.4 \%)$ male, and $42(56 \%)$ female. The diagnosis of IHD was based on resting ECG or exercise ECG records, or Echo study and coronary angiography when available. 21 Ninety eight patients had IHD, $52(61.2 \%)$ male, and $46(61.3 \%)$ female. Chronic Kidney Disease is defined as abnormalities of kidney structure or function (GFR less than $60 \mathrm{ml} / \mathrm{min} /$ $1.73 \mathrm{~m} 2$ ), present for more than three months. 22 Thirty six 
patients had pre-existing renal impairment, 32 (37.6\%) male, and $4(5.3 \%)$ female. The diagnosis of DM was according to the ADA criteria.23 Sixty six patients were diabetic, 36 (42.4\%) male, and 30 (35.3\%) female. Current Smoker is an adult who has smoked 100 cigarettes in their lifetime and presently smokes cigarettes every day (daily) or some days (nondaily).24 Fifty two patients were current smokers; 35 (41.2\%) male, and 17 (27.2\%) female. Current alcoholics defined as drinking up to 1 drink per day for women and up to 2 drinks per day for men.25 Seventeen current alcoholics found; $15(17.6 \%)$ male, and $2(2.7 \%)$ female. The diagnosis of Heart failure depended on clinical symptoms plus Echo study finding and ejection fraction ratio.26 Thirty five patients had pre-existing heart failure; 31 (36.5\%) male, and $4(5.3 \%)$ female.

Statistical Analysis:

Data analysis was done by the use of IBM SPSS statistical software version 22.0 for Windows (SPSS Incorporation, Chicago, Illinois, USA), with many continuous and categorical variables. The mean value \pm SD was used for the description of the continuous variables, the frequencies and percentages for the description of the categorical variables. Chi-Square Test X2 is used to test and compare the categorical variables. The study adopts the two-tailed probability values with $(p \leq 0.05)$ to be statistically significant.

\section{Results}

In this study from 160 patients $12(7.5 \%)$ developed CIN, 7 $(8.2 \%)$ male and $5(6.6 \%)$ female. There was a significant association between age and the development of CIN (P value $=0.02)$. From 47 patients $<45$ years, only $1(4.7 \%)$ patient developed CIN and 46 (74\%) patients not; from 63 patients 45-65years old, 3 (1.9\%) patient developed CIN and $60(37.5 \%)$ had not; from 50 patients $>65$ years, $8(16 \%)$ patients developed CIN and $42(60 \%)$ had not (Table 2). Gender had no significant association with CIN development ( $\mathrm{P}$ value $=0.472)$; among 85 male patients in this study, 7 (8.2\%) patients developed CIN and $78(91.7 \%)$ had no CIN. while among 75 female patients, 5 (6.6\%) developed CIN and $70(93.4 \%)$ had not (Table 2). Hypertension was significantly associated with CIN development ( $\mathrm{P}$ value $=$ 0.02); 101 patients have hypertension, from them 11 (10.9\%) developed CIN, and 90 (89.1\%) did not; 59 patients had no history of hypertension, from them only $1(1.7 \%)$ developed CIN and 58 (98.3\%) did not (Table 2). Diabetes mellitus and CIN were significantly associated $(\mathrm{P}$ value $=0.016)$; from 66 patients with diabetes, $9(13.6 \%)$ developed $\mathrm{CIN}$, and 57 (86.4\%) not; from 94 patients with no diabetes, 3 (3.2\%) developed CIN and 91 (96.8\%) not (Table 2). The presence of IHD was significantly associated with the development of CIN ( $\mathrm{P}$ value $=0.02$ ); 98 patient had history of IHD, from them 11 (11.2\%) developed $\mathrm{CIN}$ and 87 (88.8\%) not; 62 patients had no history of IHD, from them only $1(1.6 \%)$ patient developed CIN and 61 (98.4\%) not. (Table 2)

Dyslipidemia and development of CIN were statistically significant $(\mathrm{P}$ value $=0.03) ; 102$ patients had dyslipidemia, 11 (10.8\%) developed CIN and $91(89.2 \%)$ did not; while 58 patient had no dyslipidemia, only $1(1.7 \%)$ developed CIN and $57(98.3 \%)$ did not (Table 2). Heart failure was significantly associated with the development of CIN (P value $=<0.001)$; 35 patients had heart failure, $9(25.7 \%)$ developed CIN and 26 (74.3\%) had no CIN; 125 patients had no heart failure, $3(2.4 \%)$ developed CIN and 122 (97.6\%) had not (Table 2). Preexisting renal impairment was significantly associated with CIN development (P value $=0.01)$; from36 patients $8(22.2 \%)$ developed CIN and $28(97.8 \%)$ had not; from 124 patients without preexisting renal impairment, 4 (3.2\%) developed CIN and 120 (96.8\%) had not (Table 2).

Table 2. Association between presence of CIN and characteristics of patients.

\begin{tabular}{|c|c|c|c|c|}
\hline \multirow{2}{*}{ Variables } & & \multicolumn{2}{|c|}{ Presence of CIN } & \multirow{2}{*}{$\mathbf{P}$} \\
\hline & & Yes & No & \\
\hline \multirow{3}{*}{ Age in Years } & $<45$ & $1(2.1 \%)$ & $46(97.9 \%)$ & \multirow{3}{*}{0.02} \\
\hline & $45-65$ & $3(4.7 \%)$ & $60(74 \%)$ & \\
\hline & $>65$ & $8(16 \%)$ & $42(60 \%)$ & \\
\hline \multirow{2}{*}{ Gender } & Males & $7(8.3 \%)$ & $78(91.7 \%)$ & \multirow{2}{*}{0.472} \\
\hline & Females & $5(6.6 \%)$ & $70(93.4 \%)$ & \\
\hline \multirow{2}{*}{ HTN } & Yes & $11(10.9 \%)$ & $90(89.1 \%)$ & \multirow{2}{*}{0.02} \\
\hline & No & $1(1.7 \%)$ & $58(98.3 \%)$ & \\
\hline \multirow{2}{*}{ DM } & Yes & $9(13.6 \%)$ & $57(86.4 \%)$ & \multirow{2}{*}{0.016} \\
\hline & No & $3(3.2 \%)$ & $91(96.8 \%)$ & \\
\hline \multirow{2}{*}{ IHD } & Yes & $11(11.2 \%)$ & $87(88.8 \%)$ & \multirow{2}{*}{0.02} \\
\hline & No & $1(1.6 \%)$ & $61(98.4 \%)$ & \\
\hline \multirow{2}{*}{ Dyslipidemia } & Yes & $11(10.8 \%)$ & $91(89.2 \%)$ & \multirow{2}{*}{0.03} \\
\hline & No & $1(1.7 \%)$ & $57(98.3 \%)$ & \\
\hline \multirow{2}{*}{ Preexisting HF } & Yes & $9(25.7 \%)$ & $26(74.3 \%)$ & \multirow{2}{*}{$<0.001$} \\
\hline & No & $3(2.4 \%)$ & $122(97.6 \%)$ & \\
\hline \multirow{2}{*}{$\begin{array}{l}\text { Preexisting renal } \\
\text { impairment }\end{array}$} & Yes & $8(22.2 \%)$ & $28(97.8 \%)$ & \multirow{2}{*}{0.01} \\
\hline & No & $4(3.2 \%)$ & $120(96.8 \%)$ & \\
\hline
\end{tabular}

CIN development was significantly affected by smoking $(\mathrm{P}$ value $=0.002)$; from52 smokers, 9 (17.3\%) developed CIN and 43 (82.7\%) did not; 108 patients were not smoker, from them 3 (2.7\%) patients developed CIN and 105 $(97.3 \%)$ patients had not (Table 3). CIN development and alcohol use were significantly associated ( $\mathrm{p}$ value $=0.026$ ); from17 alcohol users, 4 (23.5\%) developed CIN and 13 $(76.5 \%)$ did not; 143 patients were non-alcohol user, 8 (5.6\%) developed CIN and 135 (94.4\%) had not (Table 3).

Table 3. The association between smoking and alcohol use on CIN development.

\begin{tabular}{lllll}
\hline \multirow{2}{*}{ Variables } & & \multicolumn{2}{l}{ Presence of CIN } & \multirow{2}{*}{ P } \\
\cline { 3 - 4 } & & Yes & No & \multirow{2}{*}{0.002} \\
\cline { 3 - 4 } Smoking & Yes & $9(17.3 \%)$ & $43(82.7 \%)$ & \\
& No & $3(2.7 \%)$ & $105(97.3 \%)$ & \multirow{2}{*}{ Alcohol use } \\
& Yes & $4(23.5 \%)$ & $13(76.5 \%)$ & 0.026 \\
& No & $8(5.6 \%)$ & $135(94.4 \%)$ & \\
\hline
\end{tabular}

Type of the procedure significantly affected the development of CIN ( $\mathrm{p}$ value $=0.016$ ); 64 patient underwent diagnostic coronary interventional procedure, 1 (1.6\%) 
developed CIN and 63 (98.4\%) did not; while 96 patients underwent therapeutic coronary interventional procedure, 11 $(11.5 \%)$ developed CIN and $85(88.5 \%)$ did not (Table 4$)$. The volume of contrast agent and the development of CIN were significantly associated $(\mathrm{P}$ value $=0.001) ; 135$ patients received $<300 \mathrm{ml}, 5(3.7 \%)$ developed CIN and $130(96.3 \%)$ did not; 25 patients received $\geq 300 \mathrm{ml}, 7$ (28\%) developed CIN and 18 (72\%) not (Table 4).

Table 4. The association between the procedure type and volume of contrast on CIN.

\begin{tabular}{|c|c|c|c|c|}
\hline \multirow{2}{*}{ Variables } & & \multicolumn{2}{|c|}{ Presence of CIN } & \multirow{2}{*}{$\mathbf{P}$} \\
\hline & & Yes & No & \\
\hline \multirow{2}{*}{ Type of procedure } & Diagnostic & $1(1.6)$ & $63(98.4 \%)$ & \multirow{2}{*}{0.016} \\
\hline & Therapeutic & $11(11.5 \%)$ & $85(88.5 \%)$ & \\
\hline \multirow{2}{*}{ Volume of contrast } & $<300$ & $5(3.7 \%)$ & $130(96.3 \%)$ & \multirow{2}{*}{$<0.001$} \\
\hline & $>300$ & $7(28 \%)$ & $18(72 \%)$ & \\
\hline
\end{tabular}

\section{Discussion}

In this study, the incidence of CIN was $7.5 \%$ in patients who underwent coronary interventional procedures, which is similar to other studies [2, 27]. This result was lower than the study by Pérez-Topete et al in which the incidence was $14.2 \%$ [8]. Also our result is higher than that shown by Rihal et al that was only $3.3 \%$ [5]. This can be due to use of prophylactic measures before the procedure and sample size of each study. The presence of CIN shown to be significantly increased with increasing age of the patient with prevalence increased from $(2.1 \%)$ in patients under 45 years old to $(16 \%)$ in patients above 65 years old. This result was similar to other studies, and it is due to many factors including reduction of GFR and decrease in renal tubular function and concentration ability $[10,28]$. Gender had no significant effect on the incidence of CIN; $(8.3 \%)$ in males and $(6.6 \%)$ in females. This is supported by other studies like that by Marenzi et al [29]. Hypertension has significantly increased the risk of CIN, and this can be due to effect of high blood pressure on the arteries around the kidneys which lead to vasospasm, narrowing and hardening of these arteries, and this is similar to a study by Bartholomew et al [30]. There was significant increase in CIN prevalence in diabetic patients $(13.6 \%)$, and this result supported by other studies that show incidence of CIN between $5.7 \%-29.4 \%$, mainly due to the decrease in GFR and multiple vascular complications in these patients [31, 35]. dyslipidemia significantly increased the risk of CIN, this was supported by the study of Liu et al who studied 3632 patients. This is because LDL-C is associated with endothelial dysfunction, inflammation, and vasoconstriction, which are involved in the pathophysiology of CIN [32].

Preexisting HF shown to significantly increase the risk of CIN development in this study, which can be due to low renal perfusion [5, 30, 33]. IHD also was significantly increased the incidence rate of CIN in this study, since 11 out of the 12 patients who developed CIN had a history of IHD, sharing the same underlying mechanism with HF that lead to reduced renal perfusion $[34,35]$. This study show significant association between preexisting renal impairment and prevalence of CIN, prevalence of CIN after PCI was increased with decreasing GFR [36]. Smoking also significantly increased the frequency of CIN in this study, because smoking can increase blood pressure, activation of the sympathetic nerve, the renin-angiotensin, and the endothelin systems as well as alteration of intra renal hemodynamics [37]. This result differs from other study which found that smoking was not a significant risk factor for CIN development [30].

Type of the procedure was also important. Therapeutic procedure significantly increases the prevalence of CIN development more than diagnostic procedure. This can be attributed to the volume of contrast agent in these procedures, as therapeutic intervention take longer duration that needs larger volume of contrast agent; this is supported by a study of Kane et al [10]. Similarly, in a retrospective study of nearly 104 patients who underwent diagnostic or therapeutic PCI, those with duration of procedure more than 90 minutes shown a higher risk of CIN development, also shown that use of more than $200 \mathrm{ml}$ of contrast media was associated with further risk for development of CIN [10], and other studies correspond to these findings [30, 33, 39].

Alcohol use was shown to have significant increase in the risk of CIN; $(23.5 \%)$ of alcohol users developed CIN. This can be due to the renal tubular dysfunction that results from alcohol consumption which includes: increase urinary excretion of calcium, magnesium, and phosphate; incomplete renal tubular acidosis, and impaired urine-concentrating ability [37]. No other studies found that show a positive correlation between alcohol use and CIN development.

\section{Conclusion}

CIN is an important complication that can develop in patients undergoing cardiac catheterization, and it is aggravated by increasing age, presence of DM, HF, IHD, renal impairment, HTN, dyslipidemia, smoking and alcohol use. Also the type of procedure (therapeutic vs. diagnostic), and large volume of contrast agent are important risk factors for CIN development. There was no significant association between gender and development of CIN. So we recommend proper patient selection, appropriate type and low dose of contrast, and adequate hydration by IV normal saline to prevent CIN. 


\section{References}

[1] Mehran R, Nikolsky E. International Society of Nephrology. Kidney International (2006) 69, S11-S15. doi:10.1038/sj.ki.5000368.

[2] Parfrey P. "The clinical epidemiology of contrast-induced nephropathy," Cardio- Vascular and Interventional Radiology, vol. 28, supplement 2, pp. S3-11, 2005.

[3] McCullough PA. Contrast induced acute kidney injury. J Am Coll Cardiol. 2008; 51 (15):1419-28.

[4] Majumdar SR, Kjellstrand CM, Tymchak WJ, Hervas-Malo M, Taylor DA, Teo KK. Forced euvolemic dieresis with mannitol and furesomide for prevention of contrast-induced nephropathy in patients with CKD undergoing coronary angiography: a randomized controlled trial. Am J Kidney Dis. 2009; 54 (4): 602-609.

[5] Rihal CS, Textor SC, Grill DE, Berger M, Ting H, Best P et al. Incidence and prognostic importance of acute renal failure after percutaneous coronary intervention. Circulation 2002; 105: 2259-64.

[6] Heyman S. N, Reichman J, and Brezis M."Pathophysiology of radiocontrast nephropathy: a role for medullary hypoxia," Investigative Radiology, vol. 34, no. 11, pp. 685-91, 1999.

[7] Dickenmann M, Oettl T, and Mihatsch M. J. "Osmotic nephrosis: acute kidney injury with accumulation of proximal tubular lysosomes due to administration of exogenous solutes," American Journal of Kidney Diseases, vol. 51, no. 3, pp. 491-503, 2008.

[8] Pérez-Topete SE, Miranda-Aquino K, Gasca-Luna, MN, and Elizondo-Adamchik HE. Contrast- Induced nephropathy in patients undergoing percutaneous coronary intervention. Revista Mexicana de Cardiología. Vol. 27 No. 2.64-70, 2016.

[9] Wichmman JL, Katzberg RW, Litwin SE, Zwerner P, Cecco $\mathrm{CN}$, Vogl TJ et al. Contrast-Induced Nephropathy. Circulation. 2015; 132: 1931-36.

[10] Kane G. C, Doyle B. J, Lerman A, Barsness G. W, Best P. J, and Rihal C. S. "Ultra-low contrast volumes reduce rates of contrast-induced nephropathy in patients with chronic kidney disease undergoing coronary angiography," Journal of the American College of Cardiology, vol. 51, no. 1, pp. 89-90, 2008.

[11] ACR committee on drugs and contrast media. ACR manual on Contrast media, Version 10. 1. American college of radiology. Published 2015 Accessed December 26, 2016.

[12] Brar SS, Aharonian V, Mansukhani P, et al. Haemodynamicguided fluid administration for the prevention of contrastinduced acute kidney injury: the POSEIDON randomised controlled trial. Lancet. 2014; 383 (9931):1814-23.

[13] Zoungas S, Ninomiya T, Huxley R, et al. Systematic review: sodium bicarbonate treatment regimens for the prevention of contrast-induced nephropathy. Ann Intern Med. 2009; 151 (9):631-38.

[14] ACT Investigators. Acetylcysteine for prevention of renal outcomes in patients undergoing coronary and peripheral vascular angiography: main results from the randomized Acetylcysteine for Contrast-induced nephropathy Trial (ACT).
Circulation. 2011;124 (11):1250-59.

[15] Patti G, Nusca A, Chello M, et al., "Usefulness of statin pretreatment to prevent contrast-induced nephropathy and to improve long-term outcome in patients undergoing percutaneous coronary intervention," American Journal of Cardiology, vol. 101, no. 3, pp. 279-85, 2008.

[16] Cruz DN, Goh CY, Marenzi G, et al. Renal replacement therapies for prevention of radiocontrast-induced nephropathy: a systemic review. Am J Med. 2012 Jan; 125 (1):66-78.

[17] Marenzi G, Lauri G, Campodonico J, et al. "Comparison of two hemofiltration protocols for prevention of contrast induced nephropathy in high-risk patients," American Journal of Medicine, vol. 119, no. 2, pp. 155-62, 2006.

[18] Levey AS and Stevens LA. Estimating GFR Using the CKD Epidemiology Collaboration (CKD-EPI) Creatinine Equation: More Accurate GFR Estimates, Lower CKD Prevalence Estimates, and Better Risk Predictions. Am J Kidney Dis. 2010 April; 55 (4): 622-7.

[19] Catapano A, Graham I, Backer G, Wiklund O, John Chapman M, Drexel H, et al: 2016 ESC/EAS Guidelines for the Management of Dyslipidaemias. European Heart Journal doi:10.1093 /eurheartj/ehw272.2016.

[20] James PA, Oparil S, Carter BL, Cushman WC, DennisonHimmelfarb C, Handler J, et al. 2014 evidence-based guideline for the management of high blood pressure in adults: report from the panel members appointed to the Eighth Joint National Committee (JNC 8). JAMA. 2014 Feb 5; 311 (5):507-20.

[21] Fihn SD, Blankenship JC, Alexander KP, Bittl JA, Byrne JG, Fletcher BJ, et al. 2014 ACC/AHA/AATS/PCNA/SCAI/STS focused update of the guideline for the diagnosis and management of patients with stable ischemic heart disease: a report of the American College of Cardiology/American Heart Association Task Force on Practice Guidelines, and the American Association for Thoracic Surgery, Preventive Cardiovascular Nurses Association, Society for Cardiovascular Angiography and Interventions, and Society of Thoracic Surgeons. J Am Coll Cardiol 2014; 64:1929-49.

[22] KDIGO 2012 Clinical Practice Guideline for the Evaluation and Management of Chronic Kidney Disease, Kidney International Supplement, Vol 3, ISSUE 1, January (1) 2013.

[23] American Diabetes Association. Diagnosis and Classification of Diabetes Mellitus. Diabetes Care 2010 Jan; 33 (1): S62S69.

[24] US Centers for Disease Control and Prevention (2010). Health behaviors of adults: United States, 2005-2007. Vital and Health Statistics, Series 10, Number 245, Appendix II, p. 80 .

[25] Dietary Guidelines for Americans 2015-2020," U.S. Department of Health and Human Services and U.S. Department of Agriculture.

[26] McMurray JJ, Adamopoulos S, Anker SD, et al. ESC Guidelines for the diagnosis and treatment of acute and chronic heart failure 2012: The Task Force for the Diagnosis and Treatment of Acute and Chronic Heart Failure 2012 of the European Society of Cardiology. Developed in collaboration with the Heart Failure Association (HFA) of the ESC. Eur Heart J. 2012; 33:1787-1847. 
[27] Gussenhoven MJ, Ravensbergen J, van Bockel JH et al. Renal dysfunction after angiography; a risk factor analysis in patients with peripheral vascular disease. J Cardiovasc Surg (Torino) 1991; 32: 81-86.

[28] Chen S. L, Zhang J, Yei F, et al., "Clinical outcomes of contrast-induced nephropathy in patients undergoing percutaneous coronary intervention: a prospective, multicenter, randomized study to analyze the effect of hydration and acetylcysteine," International Journal of Cardiology, vol. 126, no. 3, pp. 407-13, 2008.

[29] Marenzi G, Lauri G, Assanelli E, et al., "Contrast-induced nephropathy inpatients undergoing primary angioplasty for acute myocardial infarction," Journal of the American College of Cardiology. 2004. vol. 44, no. 9, pp. 1780-85.

[30] Bartholomew BA, Harjai KJ, Dukkipati S, Boura JA, Yerkey MW, Glazier S, Grines CL, O'Neill WW: Impact of nephropathy after percutaneous coronary intervention and a method for risk stratification. Am J Cardiol. 2004.93:1515-19.

[31] Bagshaw S. M and Culleton B. F. "Contrast-induced nephropathy: epidemiology and prevention," Minerva Cardioangiologica. 2006. vol. 54, no. 1, pp. 109-29.

[32] Liu YH, Liu Y, Chen JY, et al. LDL cholesterol as a novel risk factor for contrast-induced acute kidney injury in patients undergoing percutaneous coronary intervention. Atherosclerosis 2014; 237:453-9.

[33] Na KY, Kim CW, Song YR, Chin HJ, and Chae DW. "The Association between Kidney Function, Coronary Artery Disease and Clinical Outcome in Patients Undergoing Coronary Angiography," J Korean Med Sci. 2009 Jan; 24 (Suppl 1): S87-S94.
[34] Dangas G, Iakovou I, Nikolsky E, et al., "Contrast-induced nephropathy after percutaneous coronary interventions in relation to chronic kidney disease and hemodynamic variables," American Journal of Cardiology. 2005. vol. 95, no. 1, pp. 13-19.

[35] McCullough P. A, Adam A, Becker C. R, et al., "Risk prediction of contrast-induced nephropathy," American Journal of Cardiology. 2006. vol. 98, no. 6, pp. 27-36.

[36] Orth SR: Smoking-a renal risk factor. Nephron. 2000, 86: 1226.

[37] Marchi S. D, Cecchin E, Basile A, Bertotti A, Nardini R, and Bartoli E."Renal Tubular Dysfunction in Chronic Alcohol Abuse- Effects of Abstinence" N Engl J Med. Dec 1993; 329:1927-34.

[38] Khan MZ, Faruqi R. Contrast-Induced Nephropathy. J Med Sci 2018; 26: (1) 79-84.

[39] Assareh A, Yazdankhah S, Majidi S, Nasehi N, Beladi Mousavi SS. Contrast induced nephropathy among patients with normal renal function undergoing coronary angiography. J Renal Inj Prev. 2016; 5 (1):21-24. DOI: 10.15171/jrip.2016.05.

[40] Xiaole Su, Xingfang Xie, Lijun Liu, Jicheng Lv, Fujian Song, Vlado Perkovic, Hong Zhang. Comparative Effectiveness of 12 Treatment Strategies for Preventing Contrast-Induced Acute Kidney Injury: A Systematic Review and Bayesian Network Meta-analysis. American Journal of Kidney Diseases. Volume 69, Issue 1, January 2017, Pages 69-77. 